Article

\title{
Engineered Human Heavy-Chain Ferritin with Half-Life Extension and Tumor Targeting by PAS and RGDK Peptide Functionalization
}

\author{
Shuang Yin ${ }^{1}$, Yan Wang ${ }^{2}$, Bingyang Zhang ${ }^{1}$, Yiran $Q u^{1}{ }^{1}$, Yongdong Liu ${ }^{3}$, Sheng Dai ${ }^{4}$, Yao Zhang ${ }^{3}$, \\ Yingli Wang ${ }^{2, *}$ and Jingxiu $\mathrm{Bi}^{1}{ }^{1, *}$
}

check for

updates

Citation: Yin, S.; Wang, Y.; Zhang, B.; Qu, Y.; Liu, Y.; Dai, S.; Zhang, Y.; Wang, Y.; Bi, J. Engineered Human Heavy-Chain Ferritin with Half-Life Extension and Tumor Targeting by PAS and RGDK Peptide

Functionalization. Pharmaceutics 2021, 13, 521. https://doi.org/10.3390/ pharmaceutics13040521

Academic Editors: Francisco José Ostos, José Antonio Lebrón, Pilar López-Cornejo and Patrick J. Sinko

Received: 24 February 2021

Accepted: 6 April 2021

Published: 9 April 2021

Publisher's Note: MDPI stays neutral with regard to jurisdictional claims in published maps and institutional affiliations.

Copyright: (C) 2021 by the authors. Licensee MDPI, Basel, Switzerland. This article is an open access article distributed under the terms and conditions of the Creative Commons Attribution (CC BY) license (https:/ / creativecommons.org/licenses/by/ $4.0 /)$.
1 School of Chemical Engineering and Advanced Materials, The University of Adelaide, Adelaide SA5005, Australia; shuang.yin@adelaide.edu.au (S.Y.); bingyang.zhang@adelaide.edu.au (B.Z.); yiran.qu@adelaide.edu.au (Y.Q.)

2 School of Chinese Medicine and Food Engineering, Shanxi University of Traditional Chinese Medicine, Jinzhong 030619, China; wangyan81823@aliyun.com

3 State Key Laboratory of Biochemistry Engineering, Institute of Process Engineering, Chinese Academy of Sciences, Beijing 100190, China; ydliu@ipe.ac.cn (Y.L.); zhangyao@ipe.ac.cn (Y.Z.)

4 Department of Chemical Engineering, Brunel University London, Uxbridge UB8 3PH, UK; sheng.dai@brunel.ac.uk

* Correspondence: wyl@sxtcm.edu.cn (Y.W.); jingxiu.bi@adelaide.edu.au (J.B.)

Abstract: Ferritin, one of the most investigated protein nanocages, is considered as a promising drug carrier because of its advantageous stability and safety. However, its short half-life and undesirable tumor targeting ability has limited its usage in tumor treatment. In this work, two types of functional peptides, half-life extension peptide PAS, and tumor targeting peptide RGDK (Arg-Gly-Asp-Lys), are inserted to human heavy-chain ferritin (HFn) at C-terminal through flexible linkers with two distinct enzyme cleavable sites. Structural characterizations show both HFn and engineered HFns can assemble into nanoparticles but with different apparent hydrodynamic volumes and molecular weights. RGDK peptide enhanced the internalization efficiency of HFn and showed a significant increase of growth inhibition against $4 \mathrm{~T} 1$ cell line in vitro. Pharmacokinetic study in vivo demonstrates PAS peptides extended ferritin half-life about 4.9 times in Sprague Dawley rats. RGDK peptides greatly enhanced drug accumulation in the tumor site rather than in other organs in biodistribution analysis. Drug loaded PAS-RGDK functionalized HFns curbed tumor growth with significantly greater efficacies in comparison with drug loaded HFn.

Keywords: ferritin; drug delivery; tumor targeting; half-life extension

\section{Introduction}

Ferritin is one of the most attractive protein nanocages for drug delivery, due to its extraordinary thermal and chemical stability. In mammals, ferritin is a $12 \mathrm{~nm}$ sphere with an $8 \mathrm{~nm}$ cavity, made up of 24 subunits [1]. Two types of ferritin subunits exist in mammal tissues, called heavy-chain (H-chain) and light-chain (L-chain) (21 kDa and $19 \mathrm{kDa}$ ), respectively. Both two types of subunits consist of five $\alpha$-helices (helices A-E), one long loop connecting helix $\mathrm{B}$ and $\mathrm{C}$ (BC loop) and three turns connecting helices. Exposed BC loop of Human H-chain ferritin (HFn) has a binding site of human transferrin receptor 1 (TfR1) and gives rise to an intrinsic tumor active targeting ability [2]. Researchers have loaded various chemotherapeutics into $\mathrm{H}$-chain ferritin and explored its anti-tumor efficacy. For example, 5-fluorouracil attached Au nanoparticles inside ferritin decreased $\mathrm{IC}_{50}$ against HepG2 cells by 15 times [3]. A single dose of doxorubicin (DOX) loaded HFn (HFn/DOX) successfully inhibited TfR1 overexpressed HT-29 human colon cancer cells growth in mice [4]. Neuronal drugs carbachol and atropine loaded ferritin is proven to be able to regulate pancreatic cancer progression [5]. 
In spite of ferritin's multiple advantages, it is still facing challenges as a drug nanocarrier. It has a half-life in circulation of approximate $2 \mathrm{~h}$ in rats, shorter than the majority of other drug nanocarriers because of its relatively small particle size. Wang fused albumin binding domain (ABD) to increase ferritin half-life to $17.2 \mathrm{~h} \mathrm{[6].} \mathrm{In} \mathrm{addition,} \mathrm{the} \mathrm{innate}$ tumor targeting ability of HFn cannot be guaranteed in all tumors. The expression level of its receptor, human TfR1, varies in different tumor cell lines and in different stages of tumor progression $[7,8]$. Head and neck cancer, colorectal cancer and cervical cancer tissues have the highest expression level of human TfR1, whilst no human TfR1 was detected in carcinoid, prostate and testicular tumor tissues [9]. Human TfR1 is also ubiquitously expressed in healthy human tissues, such as bone marrow, lung, colon and liver, to import iron into cells, so the usage of HFn has the risk of undesired drug accumulation in healthy tissues.

To address (1) the short half-life and (2) the limited tumor targeting ability of HFn, two functional peptides were fused to HFn subunit C-terminal to construct three functionalized HFns (HFn-PAS, HFn-GFLG-PAS-RGDK and HFn-PLGLAG-PAS-RGDK). One peptide, PAS peptide, comprises repetitive $P, A$ and $S$ residues. It was designed by Schlapschy, and aimed to mimic poly ethylene glycol (PEG) [10]. In three previous studies, Falvo et al. have fused 40 aa and 75 aa PAS peptides to human ferritin subunit at N-terminal to increase halflife in circulation [11-13]. Another peptide is a tetrapeptide named as RGDK. It belongs to tumor penetration peptide (TPP) and possesses two functions. RGDK enhances drug tumor delivery, and drug distribution inside whole tumor tissue instead of only tumor cells alongside tumor vessels [14]. It specifically binds to two receptors, integrin $\alpha v \beta 3 / 5$ and neuropilin-1, both overexpressed in a wide range of tumor cells [15]. Integrin $\alpha \mathrm{v} \beta 5$ is highly expressed in cancers such as gliomas and urothelial cancer, and neoropilin-1 expression is upregulated in ovarian cancer, colorectal cancer and stomach cancer [9]. Therefore, the addition of RGDK peptide can improve HFn tumor targeting ability and broaden HFn application. The GFLG (Gly-Phe-Leu-Gly) and PLGLAG (Pro-Leu-Gly-leu-Ala-Gly) in HFnGFLG-PAS-RGDK and HFn-PLGLAG-PAS-RGDK are enzyme cleavable sites responding to cathepsin B and matrix metalloproteinase-2/9 (MMP-2, MMP-9), respectively $[16,17]$. Both enzymes are overexpressed in tumors but Cathepsin B is located inside cell lysosome and MMP-2 is secreted outside tumor cells $[18,19]$. The PAS-RGDK functional moiety in these two dually-functionalized HFns is theoretically to be cleaved from HFn before and after cell internalization, respectively. In total, four HFn-based proteins were compared with each other to investigate the impacts of PAS and RGDK on HFn performance as a drug nanocarrier.

A total of four HFn-based proteins were expressed in Escherichia coli (E. coli), and purified. High-Performance Size Exclusion Chromatography coupled with Multiple Angle Laser Light Scattering (HPSEC-MALLS) was used to characterize protein structures. In vitro and in vivo tests were designed to compare anti-tumor drug delivery performance of four HFn-based proteins in tumors lacking overexpressed human TfR1. Therefore, 4T1, a BALB/c mice breast tumor cell line was selected; 4T1 does not express human TfR1 and overexpresses integrin $\alpha v \beta 3 / 5$ and neuropilin-1 [20,21]. Cellular uptake assay investigated RGDK functionalization impact on 4T1 cellular internalization efficiency. Intracellular distribution monitored if drug can be released from proteins and enter nucleus for killing tumor cells after internalization. Cytotoxicity assay compared $\mathrm{IC}_{50}$ values of drug carried by four HFn-based proteins. Pharmacokinetic study mainly assessed PAS impact on halflife in circulation. Biodistribution study assessed tumor targeting ability of four HFn-based proteins. In vivo anti-tumor test was conducted to compare the tumor growth inhibition efficacy of DOX carried HFn and functionalized HFns.

\section{Materials and Methods}

\subsection{Materials}

A total of four recombinant HFn-based proteins (HFn, HFn-PAS, HFn-GFLG-PASRGDK and HFn-PLGLAG-PAS-RGDK) were expressed in Escherichia coli (E. coli) BL21 (DE3). HFn-PAS was constructed by inserting a 15 aa flexible linker (GGGSGGGTGGGSGGG), an 
enzyme-cleavable site GFLG, a 40 aa PAS peptide (ASPAAPAPAPAAPAPSAPAASPAAPAPASPAAPAPSAPA) together with another 5 aa flexible liner (GGSGG) to HFn Subunit C-terminus. HFn-GFLG-PAS-RGDK was constructed by adding RGDK tretapeptide to HFn-PAS C-terminus. HFn-PLGLAG-PAS-RGDK, was designed by substitution of enzymecleavable site GFLG in HFn-GFLG-PAS-RGDK by a six residue MMP-2 cleavable site PLGLAG. Proteins were purified using a two-step pathway. Briefly, HFn was purified by heat-acidic precipitation at $60^{\circ} \mathrm{C}, \mathrm{pH} 4.55 \mathrm{~min}$ followed by butyl fast flow hydrophobic interaction chromatography (GE Healthcare, Waukesha, WI, USA). The other three functionalized HFns were purified by heat-acidic precipitation at $60^{\circ} \mathrm{C}, \mathrm{pH} 4.55 \mathrm{~min}$ followed by mono $\mathrm{Q}$ ion-exchange chromatography (GE Healthcare, Waukesha, WI, USA).

Doxorubicin hydrochloride (DOX) was purchased from Dalian Meilun Biotechnology (Dalian, China). 4T1 cells were purchased from Cellbank (Sydney, NSW, Australia). RPMI1640 medium, penicillin-streptomycin solution $(100 \times)$, fetal bovine serum $(\mathrm{FBS}), 0.25 \%$ trypsin-EDTA $(1 \times)$ solution, Hoechst 33258 reagent and MTT reagent were purchased from Invitrogen (Thermo Scientific, Adelaide, SA, Australia). Propidium iodide and trypan blue solution were bought from Sigma-Aldrich (Sydney, NSW, Australia). All of the other reagents were of analytical reagent quality. Mili $Q$ water was utilized throughout the whole procedure, produced by Merck Mili Q direct (Melbourne, VIC, Australia).

\subsection{HPSEC-MALLS Characterization of Purified Proteins and DOX Loading}

The four protein purities were analyzed by reducing 12\% SDS-PAGE (Bio-Rad, Gladesville, NSW, Australia). Sizes and molecular weights (Mws) were measured by HPSECMALLS. In HPSEC-MALLS analysis, TSK G4000 SWxl column (Tosoh bioscience, Tokyo, Japan) was connected to HPLC (Shimadzu, Melbourne, VIC, Australia) coupled with DAWN MALLS and Optilab refractive index (RI) detector (Wyatt, Santa Barbara, CA, USA). Equilibration buffer was $20 \mathrm{mM}$ phosphate buffer (PB), $0.1 \mathrm{M} \mathrm{Na}_{2} \mathrm{SO}_{4}, \mathrm{pH}$ 7.0. Flow rate was $0.8 \mathrm{~mL} \mathrm{~min}-1$. Absorbance of fractions at $280 \mathrm{~nm}$ was monitored. Sample loading volume was $50 \mu \mathrm{L}$.

In DOX loading, briefly, $1 \mathrm{mg} \mathrm{mL}^{-1} \mathrm{HFn}$-based protein in $20 \mathrm{mM}$ phosphate buffer, $5 \mathrm{mM}$ guanidinium chloride, $\mathrm{pH} 7.5$ was heated at $50{ }^{\circ} \mathrm{C}$ for $6 \mathrm{~h}$ with $0.2 \mathrm{mg} \mathrm{mL}-1$ DOX. Excessive DOX was separated from DOX loaded protein (protein/DOX) by desalting on Hitrap G25 desalting column (GE Healthcare, Waukesha, WI, USA) using AKTA PURE (GE Healthcare, Waukesha, WI, USA). Collected protein/DOX underwent measurement of OD280 and OD480. DOX has absorbance at both 280 and $480 \mathrm{~nm}$, and protein only has absorbance at $280 \mathrm{~nm}$. Therefore, two (2) assumptions were made: (1) OD480 protein $/ \mathrm{DOX}=$ OD480 $_{\text {DOX }}$ ( 2 ) OD280 protein $/ \mathrm{DOX}=\mathrm{OD} 280_{\mathrm{DOX}}+\mathrm{OD} 280_{\text {protein }}$. Standard OD vs. C linear curves of DOX and HFn-based proteins were determined by serial concentrations of DOX $\left(1-40 \mu \mathrm{g} \mathrm{mL}^{-1}\right)$ and proteins $\left(0.1-1.2 \mathrm{mg} \mathrm{mL}^{-1}\right)$. Standard curves were used to calculate the concentration of DOX $\left(\mathrm{C}_{\mathrm{DOX}}\right)$ and the concentration of proteins $\left(\mathrm{C}_{\text {protein }}\right)$ in protein/DOX. Consequently, the calculation of loading ratio in protein/DOX was as follows:

$$
\text { Loading ratio }=\frac{\text { number of } \mathrm{DOX}}{\text { number of protein }}=\frac{\mathrm{C}_{\mathrm{DOX}} \bullet \mathrm{Mw}_{\text {protein }}}{\mathrm{C}_{\text {protein }} \bullet \mathrm{Mw}_{\mathrm{DOX}}}
$$

\subsection{Cellular Uptake Test}

The $4 \mathrm{~T} 1$ cell line was cultured in RPMI-1640 medium supplemented with 10\% FBS at $37^{\circ} \mathrm{C}$ in a $5 \% \mathrm{CO}_{2}$ atmosphere. Cellular uptake test procedure was modified from a previous paper [15]. For each protein/DOX group, three different treatments were conducted to obtain three fluorescence intensities, total fluorescence, internalized fluorescence, fluorescence after RGDK peptide pre-incubation.

The procedure was as follows: (1) Cell seeding. 4T1 Cells in the exponential growth phase were seeded in 24-well plates at a density of $1 \times 10^{5}$ cells per well and cultured for $48 \mathrm{~h}$ for attachment. (2) RGDK peptide pre-incubation in wells for fluorescence after RGDK peptide pre-incubation determination. To investigate the impact of fused RGDK 
on cellular uptake characteristics, $500 \mu \mathrm{M}$ free RGDK peptide was pre-incubated with the cell for $1 \mathrm{~h}$ at $37^{\circ} \mathrm{C}$ to saturate RGDK specific receptors. (3) Drug incubation. The media with or without RGDK peptide in all wells were discarded and cells were washed with phosphate buffered saline (PBS) three times, prior to adding $100 \mu \mathrm{L}$ serum-free culture medium containing free DOX or protein/DOX $\left(15 \mu \mathrm{g} \mathrm{mL}{ }^{-1}\right.$ DOX-equivalent). Then the cells were incubated for $90 \mathrm{~min}$ at $37^{\circ} \mathrm{C}$ and washed three times with PBS to remove drugs. (4) Trypan blue quenching. In wells for internalized fluorescence and fluorescence after RGDK peptide pre-incubation determination in all five groups, cells were incubated with trypan blue $(0.25 \%$ in $0.85 \% \mathrm{NaCl})$ for $5 \mathrm{~min}$ at $25^{\circ} \mathrm{C}$, and then washed five times with PBS to remove trypan blue. (5) Detachment of cells for flow cytometry analysis. A total of $400 \mu \mathrm{L}$ of $0.25 \%$ trypsin- $0.05 \%$ EDTA solution was added to all wells for digestion for $5 \mathrm{~min}$ at $37^{\circ} \mathrm{C}$ and $2 \mathrm{~mL}$ of complete medium was added to stop the digestion. Detached cells were spun at $112 \mathrm{rcf}$ for $3 \mathrm{~min}$ at $4{ }^{\circ} \mathrm{C}$ and re-suspended in $1 \mathrm{~mL}$ PBS. In total, five microliters of propidium iodide (PI) was added to incubate with cells for $10 \mathrm{~min}$ at $25^{\circ} \mathrm{C}$ for differentiation of alive and dead cells in flow cytometry detection. (6) Flow cytometry analysis. Csampler flow cytometry (Becton Dickinson, San Jose, CA, USA) was employed to determine the mean fluorescence of 5000 cells in each sample. A cell control underwent PI staining but without drug incubation, trypan blue and RGDK peptide treatment was used for gating and parameter setting prior to sample detection. PE channel (excitation laser light: $488 \mathrm{~nm}$, emission: $578 \mathrm{~nm}$ ) was utilized for DOX fluorescence detection. Mean fluorescence intensity of each sample was recorded.

\subsection{Intracellular Distribution Analysis}

Intracellular distribution analysis was designed to monitor if DOX carried by HFnbased proteins could reach tumor cell nucleus for disruption of cell division. Exponentially growing 4T1 cells were placed on a 6-well plate at a density of $4 \times 10^{5}$ cells per well and cultured for $24 \mathrm{~h}$. One cover-glass slide was put in each well prior to seeding. The medium was then discarded and cells were treated with fresh media containing protein/DOX or free DOX ( $20 \mu \mathrm{M}$ DOX-equivalent) in $2 \mathrm{~mL}$ per well for $3 \mathrm{~h}$. Drugs in wells were then removed and cells were washed three times using PBS. Fresh complete medium was added to wells for another $36 \mathrm{~h}$ incubation. Subsequently, the cells were washed three times with PBS and fixed with $4 \%$ paraformaldehyde for $10 \mathrm{~min}$ at $25^{\circ} \mathrm{C}$. Following another three times wash with PBS, cell nucleus were stained with $0.5 \mu \mathrm{g} \mathrm{mL}{ }^{-1}$ Hoechst 33258 at $25^{\circ} \mathrm{C}$ for 5 min. A ZOE fluorescence cell imager (Bio-Rad, Gladesville, NSW, Australia) was used to visualize cells. Images of cells under bright filed channel, green channel (Excitation: 480/17 nm, Emission: 517/23 nm) and blue channel (Excitation: 355/40 nm, Emission: $433 / 36 \mathrm{~nm}$ ) were captured. Green channel and green channel monitored Hoechst 33258 and DOX signal, respectively.

\subsection{Cytotoxicity Study}

The cytotoxicity of four protein/DOX and free DOX against 4T1 cell was evaluated by MTT assays. Exponential growth-phase cells were digested by $0.25 \%$ trypsin- $0.05 \%$ EDTA, and cell density was adjusted to $1 \times 10^{5}$ cells per mL by complete medium. $100 \mu \mathrm{L}$ of cells were seeded in wells of 96-well plates. Then, four wells without cells were adopted as blank control on each plate. After incubation for $24 \mathrm{~h}$, medium was replaced with new complete medium separately containing either free DOX or protein/DOX, whose concentrations ranged from 0 to $30 \mu \mathrm{g} \mathrm{mL}^{-1}$ (equivalent DOX). Four $0 \mu \mathrm{g} \mathrm{mL}^{-1}$ DOX wells on each plate were cell control wells. After incubation for another $60 \mathrm{~h}$, the media were removed and cells were washed three times by PBS. Then, $90 \mu \mathrm{L}$ of new complete medium with $10 \mu \mathrm{L}$ of MTT solution was added to each well for another $4 \mathrm{~h}$. A total of $100 \mu \mathrm{L}$ dimethyl sulfoxide (DMSO) was added to wells to ensure complete solubilization of the formed form-azan crystals. Finally, the absorbance of the solution was measured at $595 \mathrm{~nm}$ (background: $630 \mathrm{~nm}$ ) by a Microplate Reader (Biotek, Winooski, VT, USA). Absorbance of each well $\left(A_{w e l l}\right)$ was defined as $A_{595}-A_{630}$. Cell viability (\%) were calculated using Equation (2). 
$A_{\text {cell }}$ was the $A_{\text {well }}$ of cell controls, and $A_{\text {blank }}$ was the $A_{\text {well }}$ of blank controls. $\mathrm{IC}_{50}$ value of each group was calculated using dose-response fitting in origin 9.0 software (Originlab, Northampton, MA, USA).

$$
\text { Cell viability }(\%)=\left(\mathrm{A}_{\text {well }}-\mathrm{A}_{\text {blank }}\right) /\left(\mathrm{A}_{\text {cell }}-\mathrm{A}_{\text {blank }}\right) \times 100(\%)
$$

\subsection{Pharmacokinetics Study}

All animal experiments were performed with the approval of the medical ethics committee of Shanxi University of Chinese Medicine (Approval Number 2019LL137, approval date: 13 June 2019). Specific-pathogen free Sprague Dawley rats (male, 230-250 g, SPF Biotechnology Co., Ltd. Beijing, China) were randomly assigned to six groups (three rats in each group), and administrated with PBS, free DOX and protein/DOX (3.0 mg kg DOX equivalent) separately via intravenous injection at tail vein. After injection, blood samples were collected from the retro orbital sinus at fixed time points $(10,30 \mathrm{~min}, 1$, $2,4,8,12,24,36,48 \mathrm{~h}$ ) and followed by clotting for at least $0.5 \mathrm{~h}$ at $37{ }^{\circ} \mathrm{C}$. Serum was obtained by centrifugation at $4032 \mathrm{rcf}$ for $30 \mathrm{~min}$ at $4^{\circ} \mathrm{C}$. Finally, $100 \mu \mathrm{L}$ of serum of each sample was transferred to a 96-well microplate, and the DOX contents were determined using SpectraMax i3x microplate reader (Molecular devices, San Jose, CA USA). Excitation wavelength was set at $480 \mathrm{~nm}$ and emission at $580 \mathrm{~nm}$. Meanwhile, the standard curve of the fluorescence intensity with varying concentrations of DOX in rat serum was also measured for quantitative analysis. Half-lives of DOX and protein/DOX were calculated using Drug Analysis System 2.0 software (Drug China, Shanghai, China) by fitting data in single-compartment mode.

\subsection{In Vivo Imaging}

The four HFn-based proteins were first labelled by Sulfo-cy5 NHS ester (Lumiprobe, Hunt Valley, MD, USA) with a molar ratio of 1:30 (Protein to Cy5) and the uncoupled Cy5 was removed by Hitrap G25 desalting chromatography. As 4T1 is a BALB/c breast tumor cell line, female BALB/c mice were chosen to establish tumor-bearing animal model. $1 \times 10^{6} 4 \mathrm{~T} 1$ cells in $100 \mu \mathrm{L}$ of PBS were injected into right armpit of 8 -week old female BALB/c mice (specific-pathogen free, SPF Biotechnology Co., Ltd. Beijing, China) to form mice tumor model. Each group had three mice. When tumor volume reached about $300 \mathrm{~mm}^{3}$, a $150 \mu \mathrm{L}$ sample of Cy5 or protein-Cy 5 conjugates $\left(0.2 \mathrm{mg} \mathrm{kg}^{-1}\right.$ Cy5 equivalent) was intravenously injected into the tumor-bearing mice via tail vein. After treatment, the mice were anesthetized using isoflurane at 2, 4, 6.5, 12, 24 and $52 \mathrm{~h}$ and fluorescence images were taken under excitation wavelength of $646 \mathrm{~nm}$ and emission wavelength of $662 \mathrm{~nm}$ using FX Pro in vivo imaging system (Bruker BioSpin, Carteret, NJ, USA).

\subsection{Anti-Tumor Assay}

Then, $1 \times 10^{6} 4 \mathrm{~T} 1$ cells in $100 \mu \mathrm{L}$ of PBS were injected into right armpit of 8 -week old female BALB/c mice. For in vivo inhibition of tumor progression assessment, female BALB/c mice bearing 4T1 tumors of approximate $250 \mathrm{~mm}^{3}$ in size were randomly assigned to six groups ( $n=6$ in each group) and treated with protein/DOX ( $3 \mathrm{mg} \mathrm{kg}^{-1} \mathrm{DOX}$ equivalent), free DOX (3 mg kg $\left.{ }^{-1}\right)$, or PBS via $200 \mu \mathrm{L}$ intravenous injection. The drug injection was carried out every 4 days for two doses. The volumes of tumors were measured every other day. Mice were monitored for up to 17 days post-implantation and then sacrificed. Primary tumors were harvested for ex vivo imaging.

\subsection{Statistical Analysis}

Data were presented in Mean \pm Standard deviation (SD). T-test was applied to evaluate statistical significance of results. $p$ value $<0.05$ was considered significant. 


\section{Results}

\subsection{Purified HFn-Based Protein Characterizations and Drug Loading}

The purity of each protein after purification reached above $90 \%$ based on the SDSPAGE gel (Figure 1A), calculated by density scan using software Image J [22]. The apparent subunit molecular weights of HFn-PAS, HFn-GFLG-PAS-RGDK and HFn-PLGLAG-PASRGDK on gel were higher than their theoretical molecular weights $(26 \mathrm{kDa}, 26.5 \mathrm{kDa}$ and $26.6 \mathrm{kDa}$ ), which are due to the hydration of PAS peptides. Bands of two PAS-RGDK functionalized HFns in SDS-PAGE gel were slightly higher than HFn-PAS probably due to the presence of extra residues.

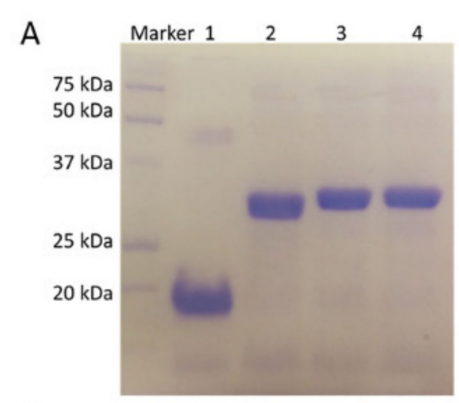

B

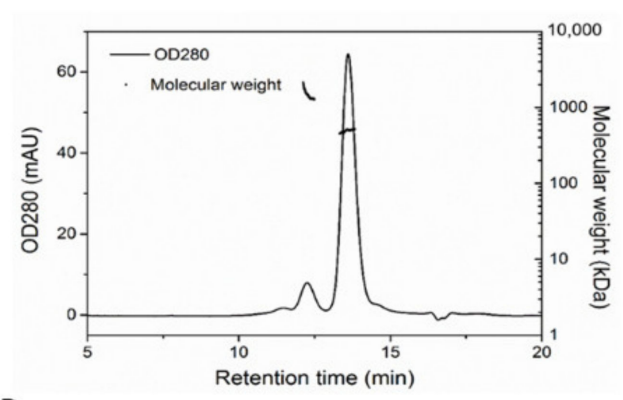

D

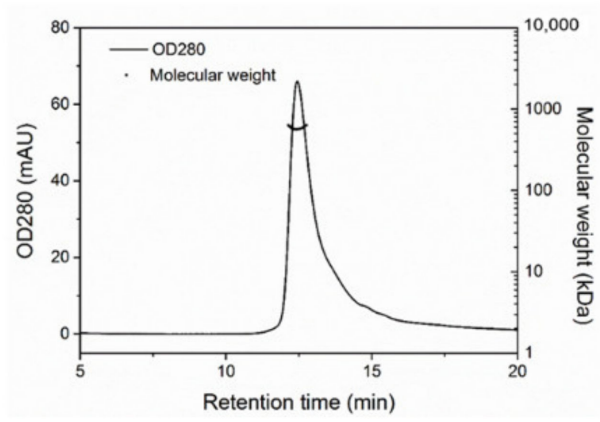

C
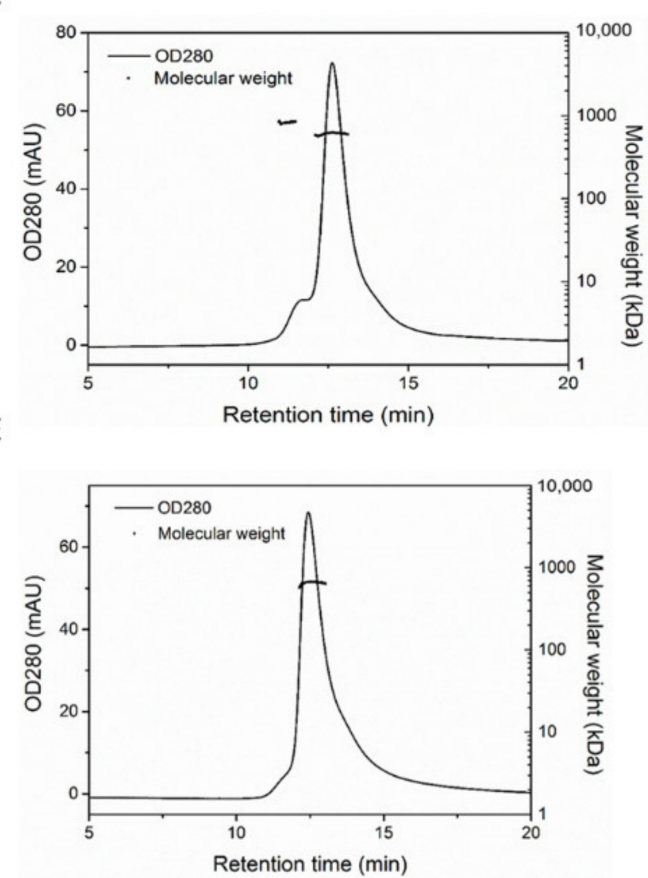

Figure 1. Characterizations of purified HFn-based proteins. (A), 12\% reducing SDS-PAGE analysis of purified proteins. Lane 1, HFn; 2, HFn-PAS; 3, HFn-GFLG-PAS-RGDK; 4, HFn-PLGLAG-PASRGDK. (B), HPSEC-MALLS chromatogram of HFn. (C), HPSEC-MALLS chromatogram of HFn-PAS. (D), HPSEC-MALLS chromatogram of HFn-GFLG-PAS-RGDK. (E), HPSEC-MALLS chromatogram of HFn-PLGLAG-PAS-RGDK.

The apparent hydrodynamic radius and molecular weight $(\mathrm{Mw})$ of four HFn-based proteins were further characterized by HPSEC-MALLS analysis. In Figure 1B-E, the horizontal Mw lines of the main peaks show the uniform Mws of all four HFn-based proteins. Table 1 lists the hydrodynamic size and $\mathrm{Mw}$ of each protein. Due to PAS peptides, HFn-PAS possessed $1.4 \mathrm{~nm}$ higher apparent hydrodynamic radius in contrast to HFn. The adding of RGDK peptide and enzyme-cleavable site into HFn slightly further increased hydrodynamic radius. HFn-GFLG-PAS-RGDK and HFn-PLGLAG-PAS-RGDK were $1.75 \mathrm{~nm}$ and $1.91 \mathrm{~nm}$ larger than HFn, respectively. MALLS determined Mw order is 
in accordance with theoretical order: HFn-PLGLAG-PAS-RGDK > HFn-GFLG-PAS-RGDK $>$ HFn-PAS $>$ HFn, and average Mw of all three proteins determined are similar to their theoretical Mw (Table 1).

Table 1. Hydrodynamic radius and molecular weight determined by HPSEC-MALLS.

\begin{tabular}{cccc}
\hline Protein & $\begin{array}{c}\text { Particle } \\
\text { Hydrodynamic } \\
\text { Radius }(\mathbf{n m})\end{array}$ & $\begin{array}{c}\text { Measured Average } \\
\text { Molecular Weight } \\
\mathbf{( k D a )}\end{array}$ & $\begin{array}{c}\text { Theoretical } \\
\text { Molecular Weight } \\
\text { (kDa) }\end{array}$ \\
\hline HFn & $6.31( \pm 0.53 \%)$ & $493.3( \pm 0.07 \%)$ & 506.0 \\
HFn-PAS & $7.72( \pm 0.54 \%)$ & $608.6( \pm 2.18 \%)$ & 625.1 \\
HFn-GFLG-PAS-RGDK & $8.06( \pm 0.55 \%)$ & $630.8( \pm 0.12 \%)$ & 636.1 \\
HFn-PLGLAG-PAS-RGDK & $8.22( \pm 0.55 \%)$ & $638.7( \pm 0.11 \%)$ & 639.3 \\
\hline
\end{tabular}

After purification, the model drug DOX was loaded by thermally induced passive diffusion. On average, incubation with DOX at $50{ }^{\circ} \mathrm{C}$ loaded 33.5, 38.4, 36.9 and 42.1 DOX in one HFn, HFn-PAS, HFn-PLGLAG-PAS-RGDK and HFn-GFLG-PAS-RGDK nanocage, respectively. HFn DOX loading ratio in this study is comparable with previous $\mathrm{pH}$-induced disassembly-reassembly method [23] and $8 \mathrm{M}$ urea method adopting HFn [4].

\subsection{Cellular Uptake Efficiency}

In cellular uptake test, we investigated the RGDK functionalization impact on cellular uptake efficiency and the mechanism. Figure 2 presents DOX fluorescence intensities of all groups. Total fluorescence of DOX measured in flow cytometry came from two sources, DOX internalized by 4T1 cells and un-specifically bound to cell membranes. Trypan blue treatment quenched the signal from membrane-bound DOX, and, therefore, a lower internalized fluorescence intensity compared with total fluorescence intensity was observed in all groups (Figure 2).

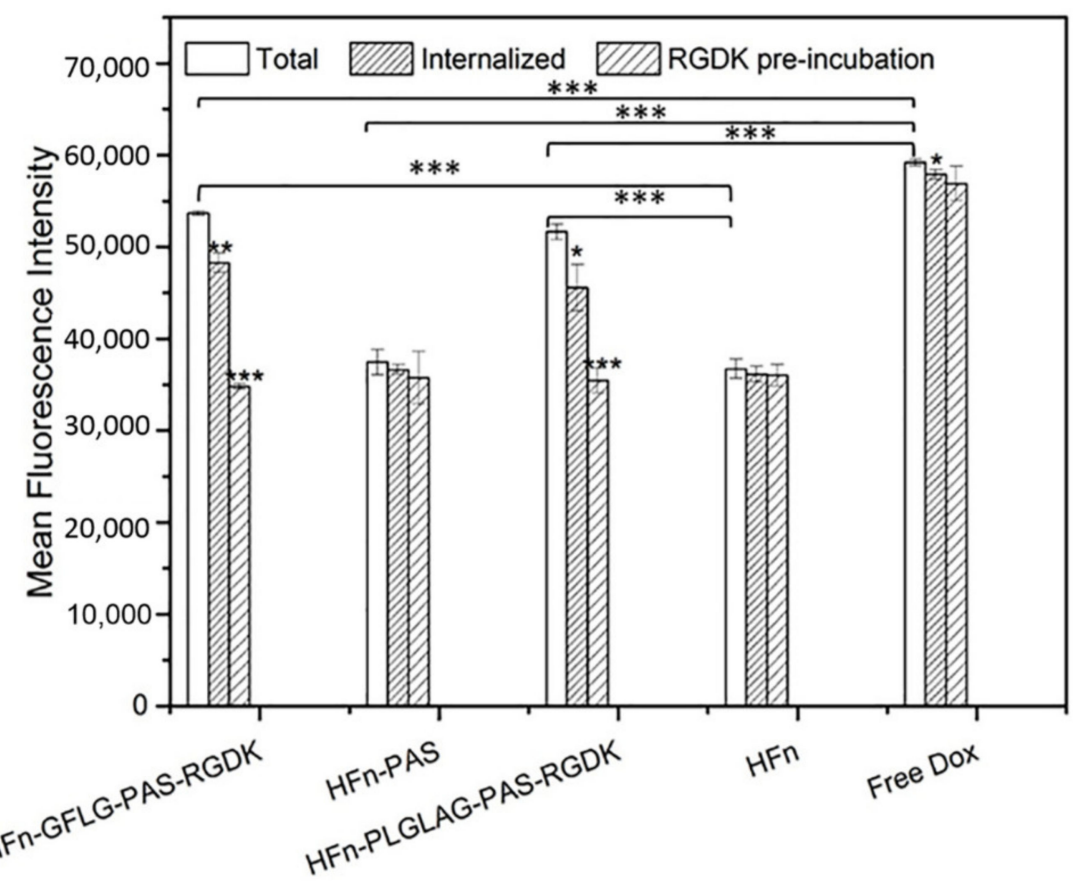

Figure 2. Mean DOX fluorescence intensity in $4 \mathrm{~T} 1$ cellular uptake test. Data were represented as mean \pm standard deviation $(n=3),^{*} p<0.05,{ }^{* *} p<0.01,{ }^{* * *} p<0.001$. Symbol ${ }^{* \prime}$ on top of column represents the significance of $p$ value between this column and the white column (total DOX fluorescence) in the same group. 
Free DOX showed significantly greater internalized cellular uptake than others. HFnGFLG-PAS-RGDK/DOX and HFn-PLGLAG-PAS-RGDK/DOX had the second highest efficiencies and were significantly different from the rest two. This means the insertion of RGDK peptide has significantly enhanced cellular uptake efficiency. HFn-PAS/DOX and HFn/DOX had similar internalized cellular uptake efficiencies. RGDK peptide preincubation treatment, with the use of excessive amount of free RGDK, is intended to mask RGDK-specific receptors, integrin $\alpha \mathrm{v} \beta 3 / 5$ and neuropilin-1, on cells to hamper RGDK-related cellular uptake. In Figure 2, the uptake of HFn-GFLG/PLGLAG-PASRGDK groups were significantly inhibited by RGDK peptide pre-incubation while in other groups no obvious difference occurred. After the pre-incubation of RGDK peptide, internalized fluorescence intensities of HFn-GFLG-PAS-RGDK/DOX and HFn-PLGLAGPAS-RGDK/DOX were similar to that of HFn/DOX and HFn-PAS/DOX. This proves that RGDK facilitated 4T1 cells' internalization of HFn-GFLG-PAS-RGDK/DOX and HFnPLGLAG-PAS-RGDK/DOX by providing RGDK-specific receptor-mediated pathway.

The difference of tumor cell uptake efficiencies lies in various uptake mechanisms. DOX is a small molecule and enters cells via passive diffusion. Passive diffusion is energyfree and concentration gradient-driven. It is quicker compared with all other internalization pathways when directly incubating drugs with cells. As 4T1 does not express human TFR1, HFn/DOX and HFn-PAS/DOX probably enter the cell through non-specific pinocytosis. In contrast with HFn/DOX and HFn-PAS/DOX, HFn-GFLG-PAS-RGDK/DOX and HFnPLGLAG-PAS-RGDK/DOX have an extra internalization pathway by binding to RGDK recognized receptors, integrin $\alpha \mathrm{v} \beta 3 / 5$ and neuropilin- 1 .

\subsection{Intracellular Distribution}

DOX is an anthracycline topoisomerase inhibitor and exerts its function mainly inside the cell nucleus [24]. Free DOX directly diffuses into nucleus and disrupts cell division after internalization, whilst the protein/DOX are supposed to first be broken down by enzymes in lysosome to release loaded DOX and then reach nucleus. Intracellular distribution test was designed to check if the drugs loaded on HFn-based proteins could enter cell nucleus to kill tumor cells. In Figure 3, the blue color indicates where cell nucleus is and green color represents the fluorescence from DOX. Clearly, the majority of DOX has entered and accumulated inside nucleus of $4 \mathrm{~T} 1$ cells in all groups, as the cyan color is the dominant color in merged images. This shows that the DOX in four protein/DOX groups could accumulate in $4 \mathrm{~T} 1$ cell nucleus, the same as free DOX.

\subsection{Functionalization Effect on Cytotoxicity}

In order to test the inhibition of protein/DOX on tumor cell proliferation, we adopted an MTT assay. All DOX loaded HFn-based proteins demonstrate obvious anti-proliferation abilities (Figure 4). Free DOX group had the lowest $\mathrm{IC}_{50}$ (Table 2) and this is due to its relatively high cellular internalization efficiency. Inhibition impacts of HFn-GFLG-PASRGDK/DOX and HFn-PLGLAG-PAS-RGDK/DOX on tumor cell growth were similar and the second strongest, HFn-PAS/DOX ranked third, and HFn/DOX showed the worst anti-proliferation effect. T-test shows there was significant differences between $\mathrm{IC}_{50}$ values of free DOX and HFn-GFLG/PLGLAG-PAS-RGDK/DOX group ( $p<0.05)$. Significant differences of $\mathrm{IC}_{50}$ values were also found between HFn-GFLG/PLGLAG-PAS-RGDK/DOX and the other two HFn-based protein/DOX groups $(p<0.05)$. That implies the RGDK in HFn-GFLG/PLGLAG-PAS-RGDK/DOX has enhanced HFn/DOX performance in terms of drug cytotoxicity towards tumor cells. 


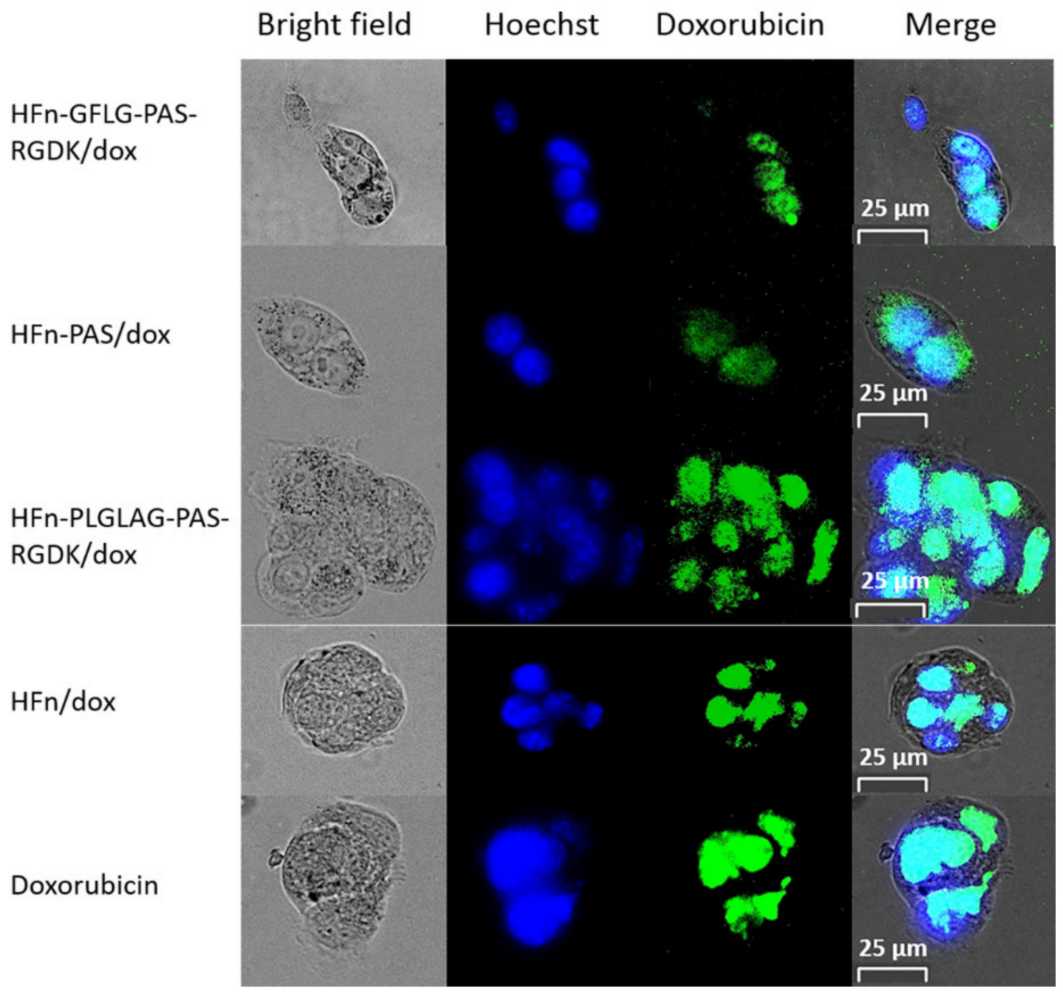

Figure 3. Intracellular distribution of DOX in 4T1 cells. Under the Bio-Rad Zoe cell imager, blue: nucleus after being stained with Hoechst 33258. Green: DOX because of its intrinsic fluorescence. Cyan: merged florescence signal.

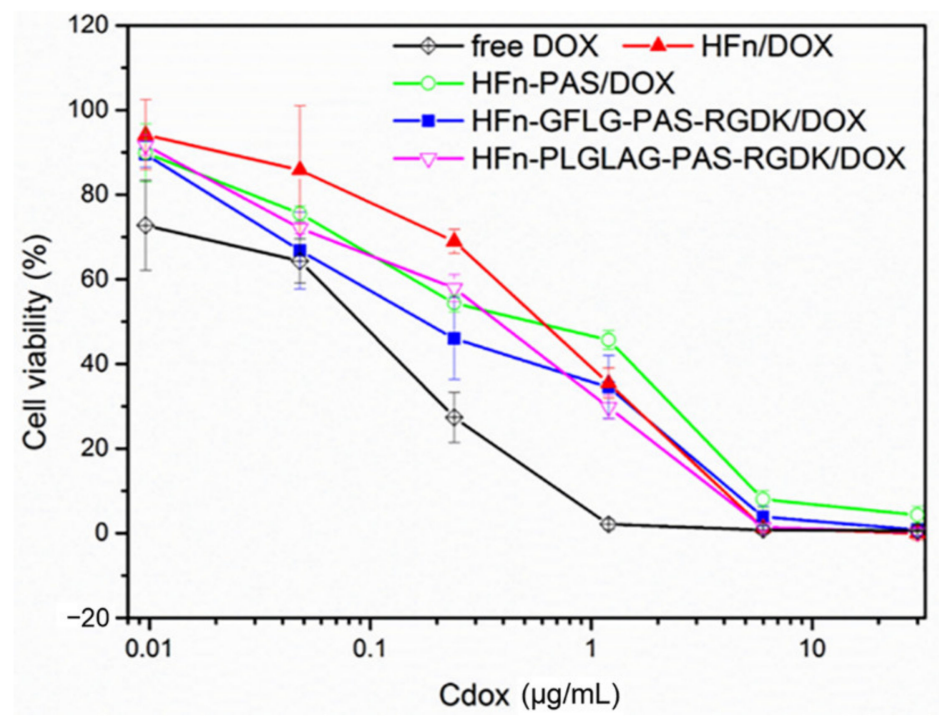

Figure 4. Proliferation inhibition on 4 T1 cells. Data were mean \pm standard deviation $(n=4)$.

Table 2. $\mathrm{IC}_{50}$ values of all groups.

\begin{tabular}{ll}
\hline Group & $\mathbf{I C}_{\mathbf{5 0}}\left(\boldsymbol{\mu} \mathbf{g} \mathbf{~ L}^{-\mathbf{1}}\right)$ \\
\hline DOX & $0.08 \pm 0.03$ \\
HFn/DOX & $0.49 \pm 0.11$ \\
HFn-PAS/DOX & $0.38 \pm 0.09$ \\
HFn-GFLG-PAS-RGDK/DOX & $0.17 \pm 0.01$ \\
HFn-PLGLAG-PAS-RGDK/DOX & $0.18 \pm 0.04$ \\
\hline
\end{tabular}




\subsection{Functionalization Effect on Pharmacokinetic Profile}

Pharmacokinetic profile of all four protein/DOX and free DOX were obtained through tail vein injection of healthy Sprague Dawley rats. Line chart of DOX concentrations in plasma over time ( $10 \mathrm{~min}-48 \mathrm{~h}$ ) is shown in Figure 5 and half-lives in circulation of all protein/DOX are listed in Table 3. Standard curve of fluorescence intensity-doxorubicin concentration is shown in supplementary material Figure S1. Plasma drug concentrations of free DOX group rats reduced rapidly right after administration (Figure 5). At $10 \mathrm{~min}$, average plasma drug concentration was $15 \mu \mathrm{g} \mathrm{mL}^{-1}$. Then, $8 \mathrm{~h}$ later, almost all free DOX was eliminated from circulation. In terms of HFn/DOX group rats, their plasma drug cleaning out speed ranked the second, with average drug concentration of $21.6 \mu \mathrm{g} \mathrm{mL}^{-1}$ at $10 \mathrm{~min}$ and below $5 \mu \mathrm{g} \mathrm{mL}^{-1}$ after $12 \mathrm{~h}$. Average plasma drug concentrations in all three functionalized $\mathrm{HFn} / \mathrm{DOX}$ group rats (approximate $35 \mu \mathrm{g} \mathrm{mL}^{-1}$ ) were more than double of those in free DOX group at $10 \mathrm{~min} .48 \mathrm{~h}$ after administration, more than $5 \mu \mathrm{g} \mathrm{mL} \mathrm{L}^{-1}$ drug still remained in plasma of all three functionalized HFn/DOX group rats. Single compartment fitting of the drug concentration-time curve was applied to evaluate drug half-life in circulation. The results show free doxorubicin only had about $25 \mathrm{~min}$ of halflife in circulation (Table 3). HFn/DOX half-life, approximate $3 \mathrm{~h}$, was 7.3 times of free DOX. PAS peptide in HFn-PAS/DOX has increased half-life almost 4.9 times (14.96 h) compared with HFn/DOX. The extra RGDK residues in HFn-GFLG-PAS-RGDK/DOX further extended the half-life to $17.61 \mathrm{~h}$. HFn-PLALGA-PAS-RGDK/DOX possessed the longest half-life, $18.93 \mathrm{~h}$. Differences in half-life of all three functionalized HFns/DOX compared with HFn/DOX and free drug were statistically significant in $t$-test $(p<0.001)$.

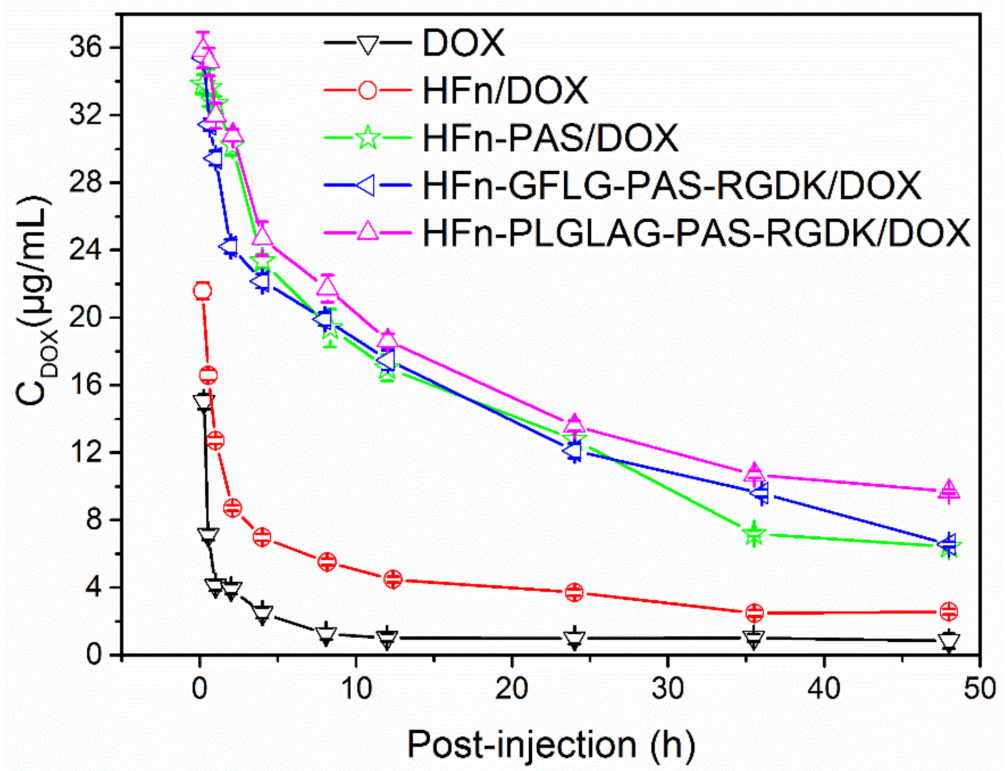

Figure 5. Plasma concentrations of protein/DOX and free DOX in Sprague Dawley rats of different groups. Data were expressed as mean $\pm \mathrm{SD}(n=3)$.

Table 3. Half-life of each protein/DOX in Sprague Dawley rats $(n=3)$.

\begin{tabular}{ll}
\hline Group & $\mathbf{T}_{\mathbf{1 / 2}} \mathbf{( h )}$ \\
\hline DOX & $0.42 \pm 0.03$ \\
HFn/DOX & $3.07 \pm 0.06$ \\
HFn-PAS/DOX & $14.96 \pm 0.29$ \\
HFn-GFLG-PAS-RGDK/DOX & $17.61 \pm 0.39$ \\
HFn-PLGLAG-PAS-RGDK/DOX & $18.93 \pm 0.61$ \\
\hline
\end{tabular}




\subsection{Functionalization Effect on Protein Biodistribution}

To monitor distribution of all HFn-based proteins in tumor-bearing mice after tail vein administration over time, we used in vivo imaging. In this analysis, fluorescence label Cy5 was attached to all employed proteins and free cy5 worked as free drug control. The reagent in use reacts with primary amine group on protein outer surface. On the outer surface of $\mathrm{HFn}$ assembly, there are 24 exposed subunit $\mathrm{N}$-terminals $-\mathrm{NH}_{2}$ groups and 144 Lys (K) residues. Due to the large number of accessible reaction sites, the possibility of cy5 blocking some or all $\mathrm{K}$ residues of RGDK in HFn-GFLG/PLGLAG-PAS-RGDK is low. The cy5 conjugation is unlikely to affect RGDK function. Real-time biodistribution of Cy5 attached proteins and free Cy5 were visualized in BALB/c mice with $4 \mathrm{~T} 1$ tumor in right armpit, and fluorescence intensities of tumor areas were recorded. Two control groups, mice injected with free cy5 and HFn-cy5 were scanned at the same time, and mice in other three groups (HFn-PAS-cy5, HFn-PLALGA-PAS-RGDK-cy5 and HFn-GFLG-PAS-RGDK-cy5) were scanned together.

Figure 6A shows the top half of the mice where there was fluorescence signal captured by camera. $4-12 \mathrm{~h}$ after injection, fluorescence of free cy 5 in liver was captured by camera (Figure 6A). At 24 and 52 h, fluorescence was barely visible. Free cy5 preferred to accumulate in the liver, perhaps due to the fact that liver is the main organ for metabolism. Theoretically, as a nanoparticle, HFn has passive tumor targeting ability. However, from the results in Figure 6A, signal of HFn-cy5 fluorescence was captured in liver rather than in tumor from 4 to $12 \mathrm{~h}$. It seems that HFn-cy5 did not show desirable tumor targeting ability and it preferred liver. The particle size of HFn is probably still too small to achieve desirable passive tumor targeting ability. No obvious fluorescence was captured at all time points in HFn-PAS-cy5 group (Figure 6A). However, as is shown in Figure 6B, there actually was fluorescence detected in tumor area. Perhaps because of the sharp contrast between signal intensities of HFn-PAS-cy5 and HFn-GFLG/PLGLAG-PAS-RGDK-cy5, lower intensity of HFn-PAS-cy5 failed to be captured by the camera under the same exposure time. In HFn-GFLG/PLGLAG-PAS-RGDK-cy5 groups, fluorescence signal was captured from $4 \mathrm{~h}$ to $52 \mathrm{~h}$ after injection (Figure 6A). The armpit fluorescence areas at 6.5, 12 and $24 \mathrm{~h}$ were larger than the area of armpit lymph node, proving the protein accumulation in tumor tissues. However, it is uncertain that if lymph node accumulation co-existed or not. Figure 6A shows that the tumor area of HFn-GFLG/PLGLAG-PAS-RGDK-cy5 groups had stronger signals than liver at all time points. At $52 \mathrm{~h}$ after injection, whilst HFn-cy5 and free cy5 were almost completely eliminated, HFn-GFLG/PLGLAG-PAS-RGDK-cy5 were still detectable in region of tumor site, implying functionalized HFns were retained in tumor by longer and stronger accumulation.

As is presented in Figure 6B, free cy5 and HFn-cy5 had the lowest tumor florescence intensity at all time points. At $2 \mathrm{~h}$, free cy 5 had a greater intensity than HFn-cy 5 but was surpassed by HFn-cy 5 afterwards. Free cy 5 tumor area fluorescence intensity peaked at $4 \mathrm{~h}$ and decreased rapidly after that, suggesting a fast clearance. HFn-cy5 achieved the highest concentration in tumor at around $4 \mathrm{~h}$ after injection (Figure 6B). The difference in free cy5 and HFn-cy5 is likely to be due to a quicker distribution and a shorter half-life of small molecule cy5 than HFn-cy5. HFn-PAS-cy5 demonstrated significantly stronger and longer lasting tumor intensities than HFn-cy5 at all detected time points $(p<0.001)$. As proven in the pharmacokinetic study, the insertion of the PAS peptide could lead to a longer half-life in circulation and probably result in the slower clearance of HFn-PAS-cy5 than HFn-cy5. The best drug targeting delivery results were from HFn-GFLG/PLGLAG-PAS-RGDK-cy5. They had significantly greater signal intensities in tumor area at all times than all the other groups $(p<0.001)$. This shows that the RGDK peptide can significantly improve HFn biodistribution. A previous study of RGDK fused Albumin binding domain has also proven the tumor targeting ability improvement of RGDK peptide in vivo. [24] Overall, both PAS and RGDK functionalization, and particularly RGDK functionalization, improved the tumor biodistribution of HFn. 


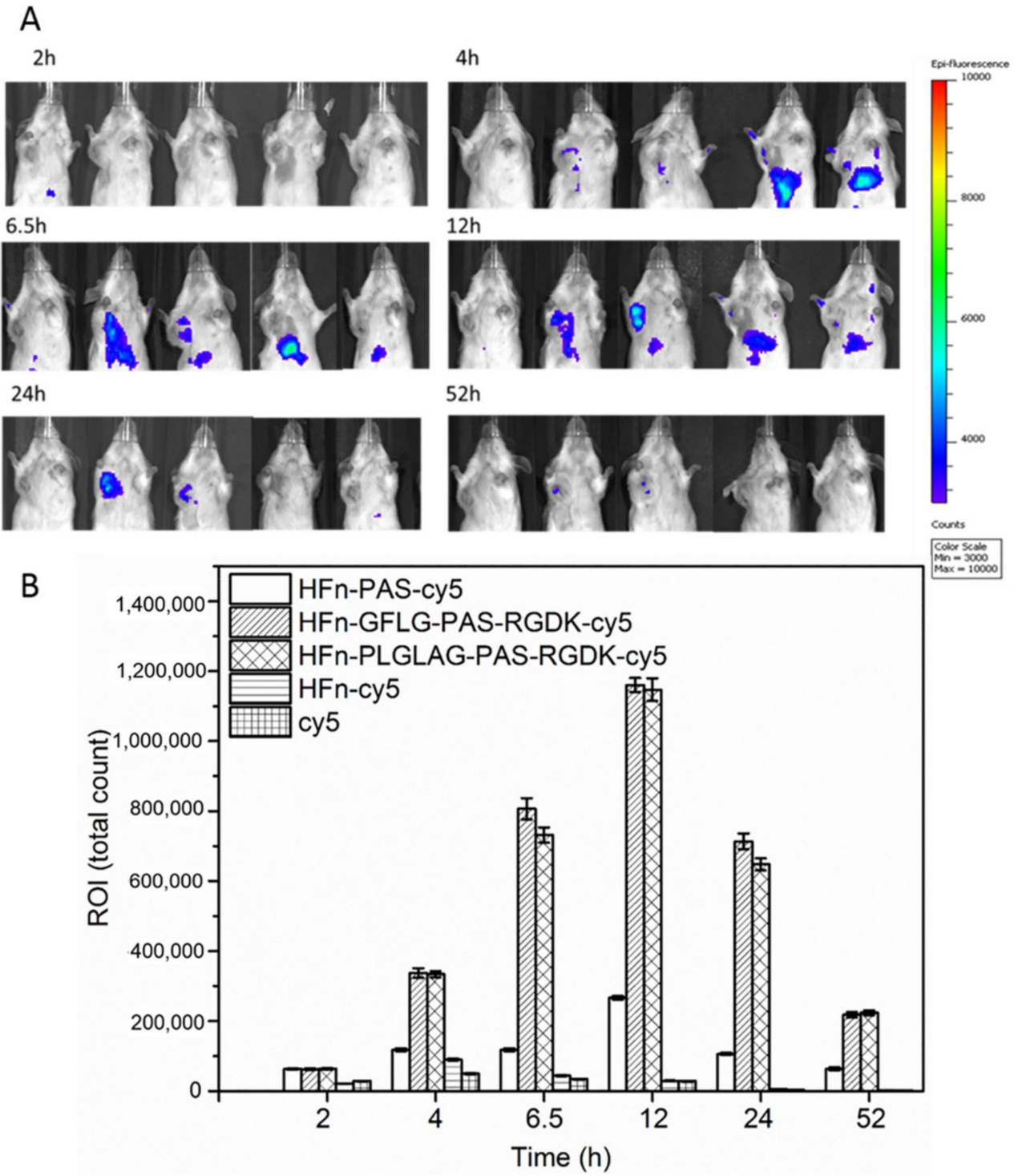

Figure 6. Biodistribution of cy5 and cy5 conjugated with HFn-based proteins. (A), in vivo fluorescence imaging of tumor-bearing mice at different time points, from left to right: HFn-PAS-cy5, HFn-GFLG-PAS-RGDK-cy5, HFn-PLGLAG-PAS-RGDK-cy5, HFn-cy5 and free cy5. (B), the sum fluorescent intensity of region of interest (ROI, tumor area) at each time point.

\subsection{Functionalization Effect on Protein/DOX Anti-Tumor Efficacy}

To compare tumor treatment efficacies of all protein/DOX and free DOX, 4T1 tumor bearing BALB/c mice model was built and 36 mice with around $250 \mathrm{~mm}^{3}$ tumor were randomly assigned into six groups. Intravenous injections of four HFn-based protein/DOX, free DOX and PBS were conducted at day 0 and day 5 . As is shown in Figure 7A, the fastest mice tumor growth rate was observed in PBS control group rats which underwent no drug treatment. The average tumor volume reached $2030 \mathrm{~mm}^{3}$ after 17 days. The second fastest tumor growth rate was in free DOX group mice and their average group tumor volume were $1667 \mathrm{~mm}^{3}$ at day 17. HFn/DOX showed a better tumor growth inhibition and at day 17 , tumor volume grew to $1521 \mathrm{~mm}^{3}$. In HFn-PAS/DOX group, mice tumor volume reached $1432 \mathrm{~mm}^{3}$ in the end. Two PAS-RGDK functionalized HFn/DOX treated group had the strongest tumor-growth inhibition. In spite of just two administrations, average tumor volume of these two group mice at day 17 were just around $1100 \mathrm{~mm}^{3}$, close to half of the volume of the PBS group tumor. 

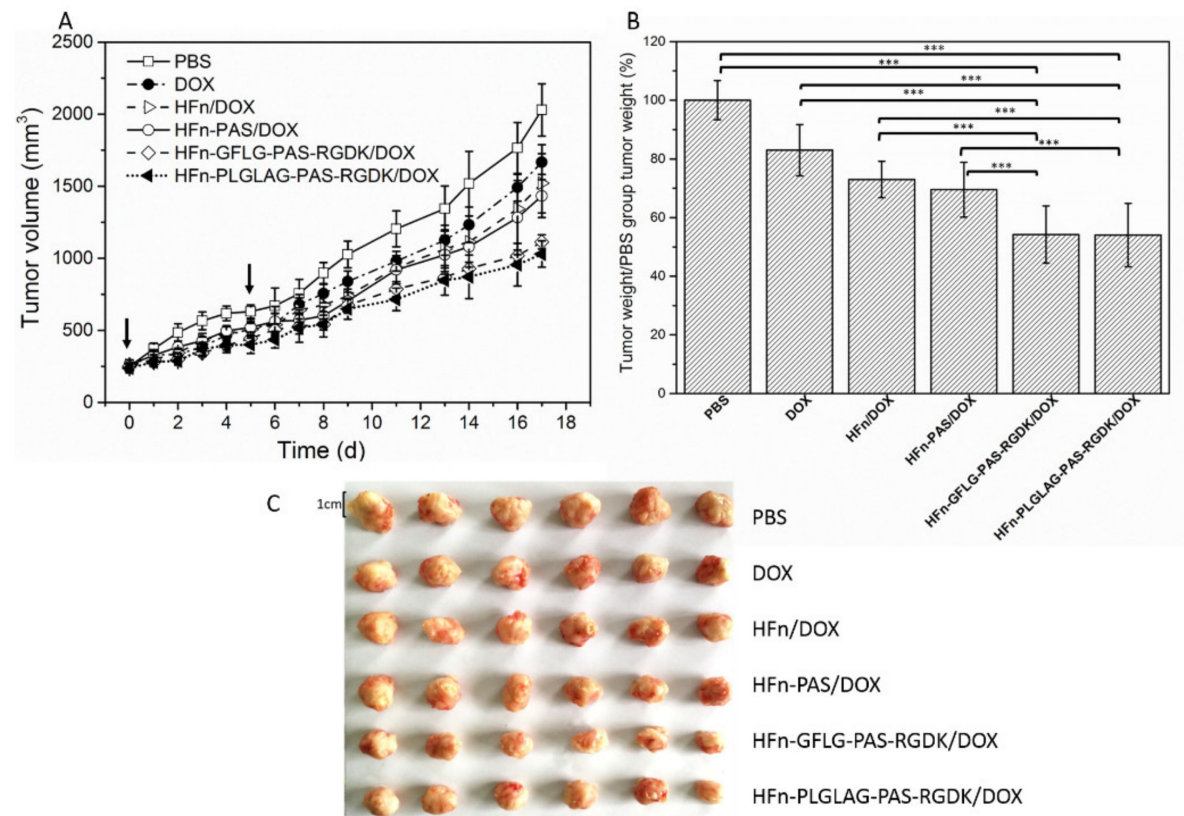

Figure 7. In vivo tumor inhibitory effects on $4 \mathrm{~T} 1$ tumor-bearing mice. (A), tumor volume change over time. (B), group tumor weight/ PBS group tumor weight $(\%)$ on day 17. ${ }^{* * *} p<0.001$. Symbol ${ }^{* \prime}$ represents the significance of $p$ value between groups. (C), the photo of excised tumor tissues on day 17. Arrows indicated the injection days; data are mean $\pm \operatorname{RSD}(n=6)$.

On day 17 , the corresponding average tumor weights were measured and the percentages of tumor weights compared with tumor weights of control PBS group mice are presented in Figure 7B. The photo of excised tumor tissues is shown as Figure 7C. Tumor weights on day 17 of HFn-GFLG-PAS-RGDK/DOX and HFn-PLGLAG-PAS-RGDK group mice were $54.2 \pm 9.7 \%$ and $54.0 \pm 10.8 \%$ of tumor weights of the control PBS group. HFn-PAS/DOX group mice had $69.5 \pm 9.4 \%$ and HFn/DOX group mice had $72.99 \pm 6.2 \%$ of PBS control group mice tumor weights. Free DOX group mice tumor weight was $82.9 \pm 8.7 \%$ of PBS control group mice. T-test results demonstrate that there were significant statistical differences between final tumor masses of protein/DOX and free DOX group. Both HFn and functionalized HFns had significantly increased DOX anti-tumor efficacy $(p<0.001)$. Compared with HFn/DOX group, HFn-PAS/DOX did not show statistical distinction $(p=0.468)$, showing that PAS functionalization alone was not enough to significantly improve anti-tumor efficacy. Masses of tumors from two PAS-RGDK protein/DOX groups, however, were significantly lower than those of both HFn/DOX group and HFn-PAS/DOX group. This indicates RGDK functionalization primarily accounts for the significant improvement of growth inhibition efficacy of 4T1 tumor. Difference between HFn-GFLG-PAS-RGDK/DOX and HFn-PLGLAG-PAS-RGDK/DOX ( $p=0.977)$ was not significant in statistical analysis. Two different enzyme-cleavable sites did not make a statistical difference in anti-tumor efficacy.

\section{Discussion}

Based on all of the results above, PAS and RGDK functionalization have both improved HFn anti-tumor performance. PAS functionalization impacts HFn mainly by extension of half-life in circulation. In pharmacokinetic study, differences in half-lives in circulation of all protein/DOX mostly stemmed from the insertion of PAS peptide. In biodistribution assay, PAS provided HFn-PAS with a longer retaining time than HFn in tumor area. Constituted by repetitive P, A and S residues, PAS peptide is hydrophilic and uncharged in neutral solutions and plasma. Circular dichroism shows it is a flexible random coil [25]. Its properties are similar to polyethylene glycol (PEG), but it is advantageous in terms of biodegradability and biocompatibility. When it is attached to another molecule, it can 
attract water molecules to increase molecule hydrodynamic volume, thereby extending half-life in circulation. PAS peptide usually has to be over 200 residues to achieve half-life extension, but because of the repeated and organized presentation manner on ferritin shell, 40 aa and 75 aa PAS peptides have been proven to be long enough when fused onto $\mathrm{N}$-terminal of ferritin subunit [11]. In this study, the enlargement of HFn hydrodynamic volume after PAS insertion was detected in HPSEC-MALLS characterization.

RGDK peptide significantly improved anti-tumor performance of HFn/DOX. In cellular uptake assay, it has increased cellular internalization efficiency through binding to specific receptors. It has also led to the best tumor targeting abilities in biodistribution assay and the greatest anti-tumor efficacy in cytotoxicity and in vivo anti-tumor assay.

Comparing HFn-GFLG-PAS-RGDK and HFn-PLGLAG-PAS-RGDK, the sequence length difference caused the minor differences in hydrodynamic volume in HPSEC-MALLS and half-life in circulation in pharmacokinetic study. However, the two enzyme-cleavable sites, GFLG and PLGLAG, did not make a significant difference in cellular uptake efficiency, and in any other in vitro and in vivo tests. This suggest the PLGLAG enzyme-cleavable site probably was not digested by MMP-2/9 before cell internalization. It could be caused by the insufficient activity of MMP-2/9 in vitro and in vivo and/or the low accessibility of PLGLAG to enzymes. A further detailed investigation of the cleavage of PLGLAG is needed.

Figure 8 illustrates the assumed tumor cell internalization pathways of all groups. Free DOX enters tumor cells via unspecific passive diffusion due to its small size (Figure 8A). The short half-life in circulation and the lack of tumor targeting ability caused a great loss of DOX before it reached tumor cells. As a result, the in vivo anti-tumor efficacy was the lowest. Both HFn/DOX and HFn-PAS/DOX enter cells through non-specific pinocytosis [26] (Figure 8B), because there is no corresponding receptor, human TfR1, on $4 \mathrm{~T} 1$ cells. Therefore, in in vitro assessments, cellular uptake assay and cytotoxicity assay, there were no statistical differences between HFn/DOX and HFn-PAS/DOX.
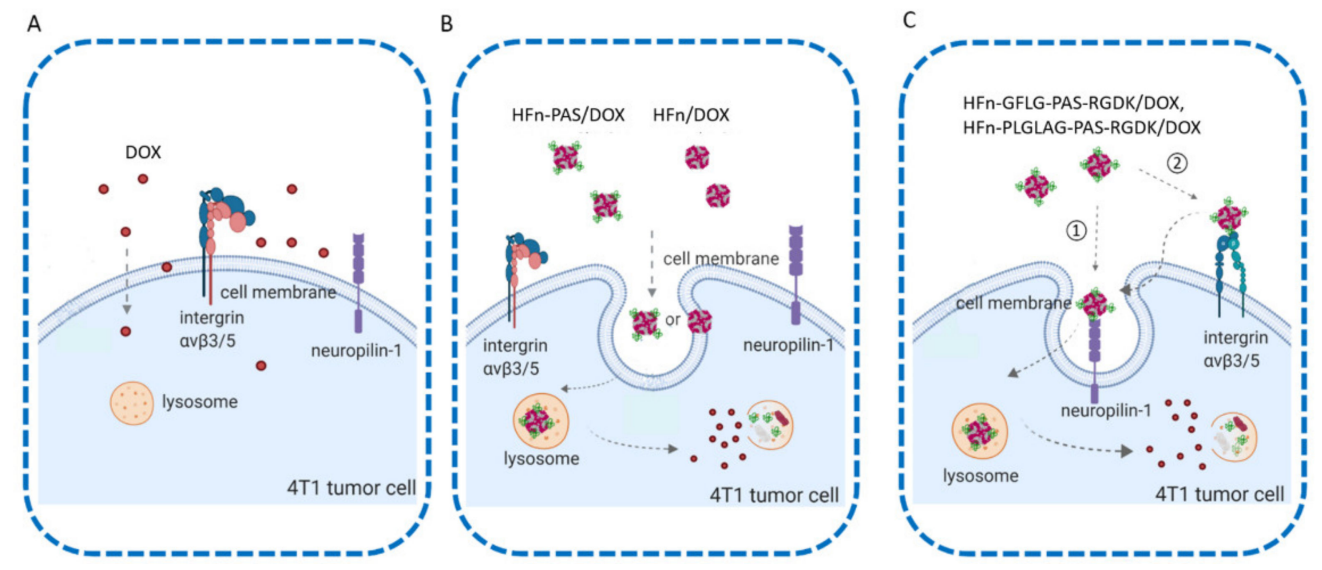

Figure 8. Schematic of different tumor cellular internalization mechanisms of DOX and protein/DOX. (A), free DOX passive diffusion pathway. (B), HFn/DOX and HFn-PAS/DOX pinocytosis internalization. (C), two possible receptor-mediated internalization pathways of HFn-GFLG-PAS-RGDK/DOX and HFn-PLGLAG-PAS-RGDK. (Created with Biorender).

HFn-GFLG-PAS-RGDK/DOX and HFn-PLGLAG-PAS-RGDK/DOX have extra drug internalization mechanisms compared with HFn/DOX and HFn-PAS/DOX (Figure 8C). Since RGDK has RGD motif and an exposed free C-terminal K residue, it can be directly recognized by both integrin $\alpha v \beta 3 / 5$ and neuropilin- 1 (NRP1), two kinds of receptors overexpressed on $4 \mathrm{~T} 1$ cells [14]. The overexpression of these two receptors has led to the increase of internalization efficiency of HFn-GFLG/PLGLAG-PAS-RGDK/DOX. As shown in Figure 8C, when HFn-GFLG/PLGLAG-PAS-RGDK/DOX reaches tumor tissue, there are two possible internalization pathways. RGDK can either directly bind to NRP1 or firstly interact with integrin $\alpha \mathrm{v} \beta 3 / 5$ and then be transferred to NRP1, followed by endocytosis. 
After that, some of the HFn-GFLG/PLGLAG-PAS-RGDK/DOX inside tumor cells would be digested in lysosome while some will travel to other cells nearby via paracellular pathway or transcytosis [27].

\section{Conclusions}

All three functionalized HFns expressed in E. coli have self-assembled into nanoparticles such as HFn. RGDK peptide has enhanced HFn tumor cell uptake efficiency and improved biodistribution, resulting in a significant improvement in anti-tumor treatment outcome. PAS has expanded HFn hydrodynamic volume and helped ferritin stay longer in circulation, which also has improved anti-tumor efficacy of ferritin. In summary, we successfully prepared and evaluated three new functionalized HFn constructs (HFn-PAS, HFn-GFLG-PAS-RGDK, HFn-PLGLAG-PAS-RGDK), especially two PAS-RGDK fused ones, which hold greater potentials as anti-tumor drug delivery nanoparticles than HFn.

Supplementary Materials: The following are available online at https:/ /www.mdpi.com/article/10.3390/ pharmaceutics13040521/s1, Figure S1: standard curve of fluorescence intensity-doxorubicin concentration in SD rat plasma.

Author Contributions: Conceptualization, J.B., Y.W. (Yinli Wang) and Y.L.; methodology, S.Y., Y.W. (Yan Wang) and B.Z.; software, S.Y.; validation, S.Y., Y.Q. and Y.Z.; formal analysis, S.Y.; investigation, S.Y.; resources, Y.L., J.B., Y.W. (Yan Wang) and Y.W. (Yinli Wang); writing-original draft preparation, S.Y.; writing-review and editing, J.B.; supervision, Y.W. (Yinli Wang), S.D., Y.L. and J.B.; project administration, J.B. and Y.W. (Yinli Wang); funding acquisition, Y.L., J.B. and Y.W. (Yinli Wang). All authors have read and agreed to the published version of the manuscript.

Funding: This work was funded by joint PhD Scholarship Scheme of the University of Adelaide and Institute of Process Engineering, Chinese Academy of Sciences, the National Natural Science Foundation of China [Grant No. 21576267], Beijing Natural Science Foundation [Grant Number 2162041], and Shanxi Education Science "1331 project" special research project (Research and Development of Traditional Chinese Medicine Micro-emulsion and New Biological Preparation).

Institutional Review Board Statement: The animal study in this work was conducted with the approval of the medical ethics committee of Shanxi University of Chinese Medicine (Approval Number 2019LL137).

Informed Consent Statement: Not applicable.

Data Availability Statement: The data presented in this study are available on request from the corresponding author.

Acknowledgments: Thanks to Iain Comerford from the University of Adelaide for his help with flow cytometry. Great appreciations to Anton Middelberg from the University of Adelaide for his helpful advice and support on this work.

Conflicts of Interest: The authors declare no conflict of interest.

\section{References}

1. He, D.; Marles-Wright, J. Ferritin family proteins and their use in bionanotechnology. New Biotechnol. 2015, 32, 651-657. [CrossRef] [PubMed]

2. He, J.; Fan, K.; Yan, X. Ferritin drug carrier (FDC) for tumor targeting therapy. J. Control Release 2019, 311-312, 288-300. [CrossRef]

3. Liu, X.; Wei, W.; Huang, S.; Lin, S.-S.; Zhang, X.; Zhang, C.; Du, Y.; Ma, G.; Li, M.; Mann, S.; et al. Bio-inspired protein-gold nanoconstruct with core-void-shell structure: Beyond a chemo drug carrier. J. Mater. Chem. B 2013, 1, 3136-3143. [CrossRef] [PubMed]

4. Liang, M.; Fan, K.; Zhou, M.; Duan, D.; Zheng, J.; Yan, X. H-ferritin-nanocaged doxorubicin nanoparticles specifically target and kill tumors with a single-dose injection. Proc. Natl. Acad. Sci. USA 2014, 111, 14900-14905. [CrossRef] [PubMed]

5. Lei, Y.; Hamada, Y.; Li, J.; Cong, L.; Wang, N.; Li, Y.; Zheng, W.; Jiang, X. Targeted tumor delivery and controlled release of neuronal drugs with ferritin nanoparticles to regulate pancreatic cancer progression. J. Control Release 2016, 232, 131-142. [CrossRef]

6. Wang, C.; Zhang, C.; Li, Z.; Yin, S.; Wang, Q.; Guo, F.; Zhang, Y.; Yu, R.; Liu, Y.; Su, Z. Extending half-life of H-ferritin nanoparticle by fusing albumin binding domain for doxorubicin encapsulation. Biomacromolecules 2018, 19, 773-781. [CrossRef] [PubMed] 
7. Corte-Rodriguez, M.; Blanco-González, E.; Bettmer, J.; Montes-Bayon, M. Quantitative analysis of transferrin receptor 1 (TfR1) in individual breast cancer cells by means of labeled antibodies and elemental (ICP-MS) detection. Anal. Chem. 2019, 91, 15532-15538. [CrossRef]

8. Prutki, M.; Poljak-Blazi, M.; Jakopovic, M.; Tomas, D.; Stipancic, I.; Zarkovic, N. Altered iron metabolism, transferrin receptor 1 and ferritin in patients with colon cancer. Cancer Lett. 2006, 238, 188-196. [CrossRef]

9. The Human Protein Atlas. Available online: https://www.proteinatlas.org/ (accessed on 16 February 2021).

10. Harari, D.; Kuhn, N.; Abramovich, R.; Sasson, K.; Zozulya, A.L.; Smith, P.; Schlapschy, M.; Aharoni, R.; Koster, M.; Eilam, R.; et al. Enhanced in vivo efficacy of a type I interferon superagonist with extended plasma half-life in a mouse model of multiple sclerosis. J. Biol. Chem. 2014, 289, 29014-29029. [CrossRef]

11. Falvo, E.; Tremante, E.; Arcovito, A.; Papi, M.; Elad, N.; Boffi, A.; Morea, V.; Conti, G.; Toffoli, G.; Fracasso, G.; et al. Improved doxorubicin encapsulation and pharmacokinetics of ferritin-fusion protein nanocarriers bearing proline, serine, and alanine elements. Biomacromolecules 2016, 17, 514-522. [CrossRef]

12. Falvo, E.; Malagrino, F.; Arcovito, A.; Fazi, F.; Colotti, G.; Tremante, E.; Micco, P.D.; Braca, A.; Opri, R.; Giuffre, A.; et al. The presence of glutamate residues on the PAS sequence of the stimuli sensitive nano-ferritin improves in vivo biodistribution and mitoxantrone encapsulation homogeneity. J. Control Release 2018, 275, 177-185. [CrossRef]

13. Falvo, E.; Damiani, V.; Conti, G.; Conti, G.; Boschi, F.; Messana, K.; Giacomini, P.; Milella, M.; Laurenzi, V.; Morea, V.; et al. High activity and low toxicity of a novel CD71-targeting nanotherapeutic named The-0504 on preclinical models of several human aggressive tumors. J. Exp. Clin. Cancer Res. 2021, 40, 63. [CrossRef]

14. Yan, F.; Wu, H.; Liu, H.; Deng, Z.; Liu, H.; Duan, W.; Liu, X.; Zheng, H. Molecular imaging-guided photothermal/photodynamic therapy against tumor by iRGD-modified indocyanine green nanoparticles. J. Control Release 2016, 224, 217-228. [CrossRef] [PubMed]

15. Wang, K.; Zhang, X.; Liu, Y.; Liu, C.; Jiang, B.; Jiang, Y. Tumor penetrability and anti-angiogenesis using iRGD-mediated delivery of doxorubicin-polymer conjugates. Biomaterials 2014, 35, 8735-8747. [CrossRef]

16. Li, H.; Qiu, Z.; Li, F.; Wang, C. The relationship between MMP-2 and MMP-9 expression levels with breast cancer incidence and prognosis. Oncol. Lett. 2017, 14, 5865-5870. [CrossRef] [PubMed]

17. Caculitan, N.G.; Ma, Y.; Zhang, D.; Kozak, K.R.; Liu, Y.; Pillow, T.H.; Sadowsky, J.; Cheung, T.K.; Phung, Q.; Haley, B. Cathepsin $\mathrm{B}$ is dispensable for cellular processing of cathepsin B-cleavable antibody-drug conjugates. Cancer Res. 2017, 77, 7027-7037. [CrossRef] [PubMed]

18. Zhong, Y.J.; Shao, L.H.; Li, Y. Cathepsin B-cleavable doxorubicin prodrugs for targeted cancer therapy (Review). Int. J. Oncol. 2013, 42, 373-383. [CrossRef]

19. Mei, L.; Zhang, Q.; Yang, Y.; He, Q.; Gao, H. Angiopep-2 and activatable cell penetrating peptide dual modified nanoparticles for enhanced tumor targeting and penetrating. Int. J. Pharm. 2014, 474, 95-102. [CrossRef]

20. Liu, X.; Jiang, J.; Ji, Y.; Lu, J.; Chan, R.; Meng, H. Targeted drug delivery using iRGD peptide for solid cancer treatment. Mol. Syst. Des. Eng. 2017, 2, 370-379. [CrossRef]

21. He, Z.; Tessier-Lavigne, M. Neuropilin is a receptor for the axonal chemorepellent Semaphorin III. Cell 1997, 90, 739-751. [CrossRef]

22. Schneider, C.A.; Rasband, W.S.; Eliceiri, K.W. NIH Image to ImageJ: 25 years of image analysis. Nat. Methods 2012, 9, 671-675. [CrossRef]

23. Kilic, M.A.; Ozlu, E.; Calis, S. A novel protein-based anticancer drug encapsulating nanosphere: Apoferritin-doxorubicin complex. J. Biomed. Nanotechnol. 2012, 8, 508-514. [CrossRef]

24. Liu, L.; Zhang, C.; Li, Z.; Wang, C.; Bi, J.; Yin, S.; Wang, Q.; Yu, R.; Liu, Y.; Su, Z. Albumin binding domain fusing R/K-X-X-R/K sequence for enhancing tumor delivery of doxorubicin. Mol. Pharm. 2017, 14, 3739-3749. [CrossRef] [PubMed]

25. Schlapschy, M.; Binder, U.; Borger, C.; Theobald, I.; Wachinger, K.; Kisling, S.; Haller, D.; Skerra, A. PASylation: A biological alternative to PEGylation for extending the plasma half-life of pharmaceutically active proteins. Protein Eng. Des. Sel. 2013, 26, 489-501. [CrossRef] [PubMed]

26. Kettler, K.; Veltman, K.; Meent, D.V.D.; Wezel, A.V.; Hendriks, A.J. Cellular uptake of nanoparticles as determined by particle properties, experimental conditions, and cell type. Environ. Toxicol. Chem. 2014, 33, 481-492. [CrossRef]

27. Feron, O. Tumor-penetrating peptides: A shift from magic bullets to magic guns. Sci. Transl. Med. 2010, 2, 34ps26. [CrossRef] [PubMed] 